\title{
STARLESS NIGHT
}

\section{Cold comfort.}

\section{BY ANDREW JOHNSTON}

A n ephemeral layer of crinkly ice coated the surface of the microphone, falling in glistening flakes as Matilda ran a gloved hand over the mic's surface. It was a sturdy device, but there was simply no way of knowing if it still functioned; even the most overzealous engineers didn't bother to plan for such conditions. The broadcasting array was still working, at least, or that's what she could glean from those instruments that were still functional. Matilda had always thought that computers were supposed to function best in a cold environment, but even a being of wire and steel must have its limitations.

Matilda drew the microphone to her face, pulling down her parka just enough to allow for speech. "Explorer Nozek, broadcasting from Rogue Object X-27881. Current astronomical location is unknown. Proximity to other objects is unknown. Time since last broadcast ..." She pushed the microphone aside just in time to stifle a delirious laugh. “... I guess I don't know how long it's been. Funny, I hadn't really thought about it until just right now, but without a star to revolve around or a nice neat rotation, these rogue planets don't have 'time' like we do back on Earth, nice neat cycles that we can chart and predict and obsess over. Different circumstances, this might be very liberating."

Matilda buried her face in the parka as she fell prey to a violent coughing fit. The 'cold' she had contracted was clearly psychosomatic - she was in a hypochondriac's dark dream, a place so frigid that no pathogen could possibly survive in the air. Nothing could live here for long, or at least that was what Matilda - what everyone on Earth - had assumed before she landed.

"Sorry about that," said Matilda, idly tapping one of the displays. "OK. Current temperature is about $-230^{\circ} \mathrm{C}$ and dropping fast as we continue to move away from all known stars. Guess I should switch over to kelvin soon, that's ... a pleasant moment, when you realize the freezing point of water has become grossly inadequate for what

$\rightarrow$ NATURE.COM

Follow Futures:

@ @NatureFutures

f go.nature.com $/ \mathrm{mtoodm}$ you are experiencing. Um ... the heat pump is still working, which is a minor miracle as it's really only built for

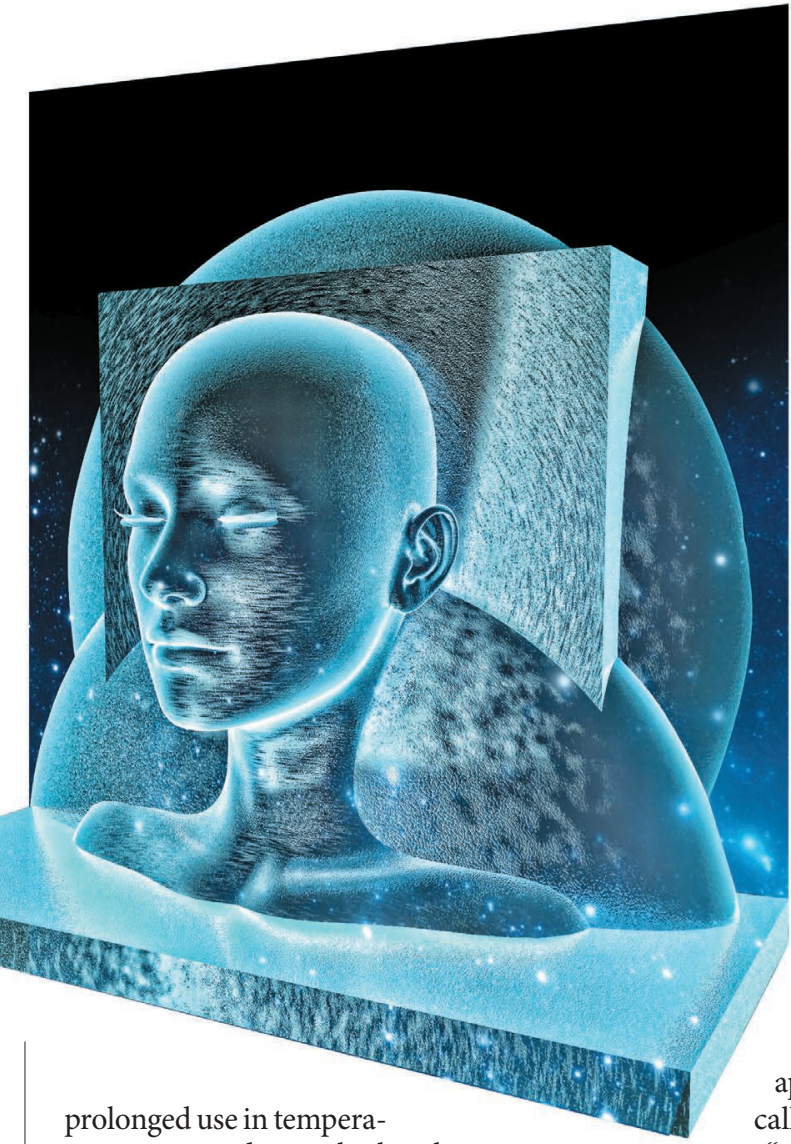

tures some 50 degrees higher than

this. I expect it'll overload and break soon, probably around the time the back-up batteries give out and - "

A strange rhythmic tapping sound split the silence, a tangle of tiny feet skittering across the metal plates in the shadows at the edge of the cramped chamber. Matilda shot a quick glance out of the corner of her eye at the new arrival but didn't halt for more than a second.

"In concluding what I suspect will be my final missive, as ... well, I have no clue where I am so there's no chance of anyone else finding me ... anyway, I'd just like to say that the Rogue Exploration Project was a terrible idea. We're never going to know how many astronauts we've killed on this little journey, but I suspect the answer is all of us. 'Oh no, sending robots isn't good enough. We need human eyes on those planets. Consider the possibilities.' I can remember saying this myself, both while drunk and stone-cold sober, so I guess this is partially on me. If you do find me, don't bother with a funeral or service, but go ahead and dig up what's under my ship. Trust me on this."

Matilda's final words vanished into another bout of coughing, one that she wilfully allowed the microphone to pick up - the better to let the recipients know what the end would look like. Terminating the broadcast, she let her head roll to one side, staring off into the shadows at the edge of the chamber.

"You come to watch me die?" said Matilda. "Come on out, don't skulk."

At first, she could see only the thing's deformed-looking eyes, those recessed pits that glimmered in the dim light. Then, with a series of clicks, it emerged into the shimmery light. First came the head, triangular and with few features aside from its eye-pits and a weird suckermouth whose mechanics were beyond knowing. Next came its slender body, jet black and covered in translucent fibrous hairs that turned rigid in time with its respiration. The odd little creature was supported by two asymmetrical lines of spindly appendages that clicked almost musically as the thing advanced.

"You alone this time, or did you bring your brothers?" Matilda sighed and slumped down in her seat, then suddenly grabbed the microphone and yanked it forward. "Come on, make a sound. So you can't speak, but can't you growl or bark or ... burble or groan or something? Can't you prove that you exist before I die? Won't you at least let me be known as the one who discovered you?"

The creature merely cocked its head, moving itself up and down on its appendages. It drew closer to Matilda like a curious dog, then backed away to size her up. There was a faint sound from the bowels of the vessel, or rather the absence of a sound that Matilda had ceased to notice.

"That would be the heat pump going." Matilda glanced at the creature as the cold enveloped her. "I guess the Universe is always going to keep its secrets, huh?"

Matilda closed her eyes and drifted off to a sleep from which she would never wake. The creature's eye-pits never left her.

Andrew Johnston is a former Pacifichopping ESL teacher currently scrapping away in the dark spiritual heart of Kansas. 